\title{
Does Poor Childhood Health Explain InCREASED Health CARE UtiLISATION AND Payments in MiddLe AND Old AGe?
}

Karine Moschetti, Karine Lamiraud, Owen O'Donnell, Alberto Holly 


\section{Does Poor Childhood Health Explain Increased Health Care Utilisation and Payments in Middle and Old Age?}

Karine Moschetti, Karine Lamiraud1, Owen O'Donnell, and Alberto Holly

\subsection{The long-lasting health care consequences of childhood conditions}

There is growing evidence of a large, positive and significant association between health experienced in childhood and that evolving in adulthood. For example, Case et al (2005), using data from a British cohort followed from birth, find that poor health in childhood is correlated with reduced health in adulthood up to the age of 42 . The association remains after controlling for socioeconomic circumstances in both childhood and adulthood. One of the many potential implications of such a correlation is that the health care costs of an ageing population will, in part, be determined by health events experienced in childhood and may be less responsive to the prevention and treatment of health problems that arise in adulthood. On a more positive note, the health care costs of ageing may be lower than anticipated since cohorts that will reach old age in the coming years have experienced better childhood health and health care than did their predecessors. This paper examines directly the extent to which health care utilisation and payments in middle and old age are predictable from childhood health experiences.

The analysis is made possible by the rich data provided by SHARELIFE, which provides detailed retrospective life histories, including health events in childhood that can be linked to the contemporaneous SHARE panel data on health, health care utilisation and payments for health care for populations aged 50+. The crossnational nature of SHARE makes it possible to examine whether the ability of childhood health to predict health care utilisation at older ages varies across European countries. This would be expected if cross-country variation in the universality and quality of health care during the childhood of the SHARE cohorts was sufficiently marked such that childhood health problems were more likely to be effectively treated within some systems than in others. The correlation between health in childhood and adulthood may also vary across countries if there was variation in the extent to which poor childhood health disrupted education. A curtailed education may have long term health consequences through health knowledge, behaviour and economic circumstances.

Examination of cross-country variation is an indirect way of investigating the extent to which the long-lasting health care consequences of childhood illness can be mitigated. A more direct approach is to test whether constrained access to 
health care in childhood is correlated with reduced health and increased health care use in later life. The SHARELIFE data are somewhat limited in the information provided on health care use in childhood, but we use that which is available to test the hypothesis.

Section 2 describes the data drawn from SHARE and SHARELIFE. Section 3 presents the association between childhood health status and health care use and payments in middle and old age, while section 4 investigates the possible mechanisms responsible for this correlation. Section 5 examines whether the association between childhood health status and health care use varies across groups of European countries. Section 6 discusses the relevance of our findings for policy and future research.

\subsection{Data}

We use health care utilisation and payment data from the first and second waves of the SHARE survey combined with retrospective data on childhood health from SHARELIFE. The analysis is based on a pooled sample of respondents for which information on all required variables is reported. The sample consists of $25^{\prime} 737$ individuals, of whom 13'438 were interviewed in both waves of SHARE, 9'528 were interviewed in wave 1 only and 2'771 were interviewed only in wave 2. All were interviewed in SHARELIFE. Overall, the sample comprises 39' 175 observations from 13 countries (Austria, Germany, Sweden, Netherlands, Spain, Italy, France, Denmark, Greece, Switzerland, Belgium, Czech Republic and Poland). The proportion of women is $56 \%$ and the mean age is 63 .

We use the following dichotomous indicators of health in childhood (defined as age less than 16): i) whether the respondent reports his/her health status during childhood as "fair" or "poor" versus "good", "very good", or "excellent": ii) whether he/she reports to have had at least one of the following childhood illnesses - polio, asthma, respiratory problems other than asthma, severe diarrhoea, meningitis/encephalitis, chronic ear problems, speech impairment and problems with vision (question HS008); iii ) whether he/she reports to have had at least one childhood illness or condition from another list - severe headaches or migraines; epilepsy, fits or seizures; emotional, nervous or psychiatric problems; broken bones, fractures; appendicitis; childhood diabetes or high blood sugar; heart trouble; leukaemia or lymphoma; cancer or malignant tumour (question HS009); iv) a dichotomous variable indicating whether he/she had at least one inpatient stay of one month or longer, or had three or more hospital stays over a period of 12 months, during childhood. Furthermore, we use whether the respondent's parents smoked during his/her childhood as an indicator of exposure to a health risk. Finally, access to health care during childhood is measured by whether or not the respondent reports that $\mathrm{s} / \mathrm{he}$ did not have a usual source of care during childhood. Admittedly, this is a rather crude indicator of constrained access to care, but, as 
will be demonstrated, it is nonetheless informative in explaining health and health care use in adulthood.

Health care utilisation (HCU) in middle and old age is measured by the reported number of contacts with a physician (either a General Practitioner or a specialist) during the previous 12 months. Out-of-pocket (OOP) payments include non-refundable expenses for inpatient care, outpatient care, prescribed drugs and nursing homes and monetary values are expressed in Euros, adjusted for purchasing power parity. This is more comprehensive than our measure of utilisation, in the sense that it covers more types of medical treatment. However, it will vary not only with the quantity of care but also with the prices paid, which vary with insurance coverage that, in turn, is dependent on country, age, health condition and economic circumstances. Apart from their correlation with utilisation, OOP payments are of interest because of the burden they place on the household. We seek to establish whether individuals afflicted by illness in childhood are carrying an economic burden of this, in terms of increased payments for health care, in middle and old age.

Health status in middle and old age is measured by standard indicators: i) selfassessed health status collapsed into a binary indicator distinguishing goodexcellent health from poor-fair health; ii) whether the respondent suffers from a diagnosed chronic illness; iii) whether he/she reports at least two symptoms (see note to Table 23.1 for list) iv) the number of limitations in activities of daily living and instrumental activities of daily living. In addition, we control for smoking status in adulthood through indicators of currently smoking and of having stopped smoking

Measures of socioeconomic status in adulthood are education level, collapsed into three categories (Low level (International Classification of Education ISCED - 1-2), Intermediate level (ISCED 3-4), High level (ISCED 5-6)), log annual gross household income per capita and employment status represented by an indicator of whether the individual is not working and is below the age of 65 . Moreover, all specifications and models estimated include country dummy variables, as well as gender-age group dummies using five age groups: [45-54[, [5564[, [65-74[, [75-84[, [85+[.

\subsection{Association between childhood health and health care utilisation in adulthood}

We begin by describing the total association between health status in childhood and doctor visits and private OOP payments for health care in middle and old age. Figure 23.1 plots the mean number of doctor visits by age for those reporting good-excellent health (brown) and those reporting poor-fair health (blue) during childhood. The profiles are strikingly different. Around the age of 50, those who report poor-fair health during childhood consult the doctor at least $60 \%$ more than 
those who report good-excellent health in childhood. Those reporting goodexcellent health in childhood are above the age of 70 before they reach the utilisation rate of those reporting poor-fair health at age 50. There is a clear upward trend in doctor visits with age for the sample reporting good-excellent health in childhood. This is much less apparent for the group reporting poor-fair health. Consequently, by age 80 there is no difference between the groups in their use of doctors.

In early middle age individuals who report poor health in childhood appear to be already in a very poor state of health and are making intensive use of health care. They may already have contracted the chronic conditions that will materialise only in old age for individuals who were healthy in childhood. If so, this points to very large differences in inherent health, which are already evident in childhood. However, it could also be that causality runs in the opposite direction. It may be that individuals experiencing severe health problems in middle age and making frequent use of health care are more likely to remember childhood health problems and to report poor health in childhood.

Figure 23.1: $\quad$ Mean number of doctor visits by age split by self reported health status before Age 16

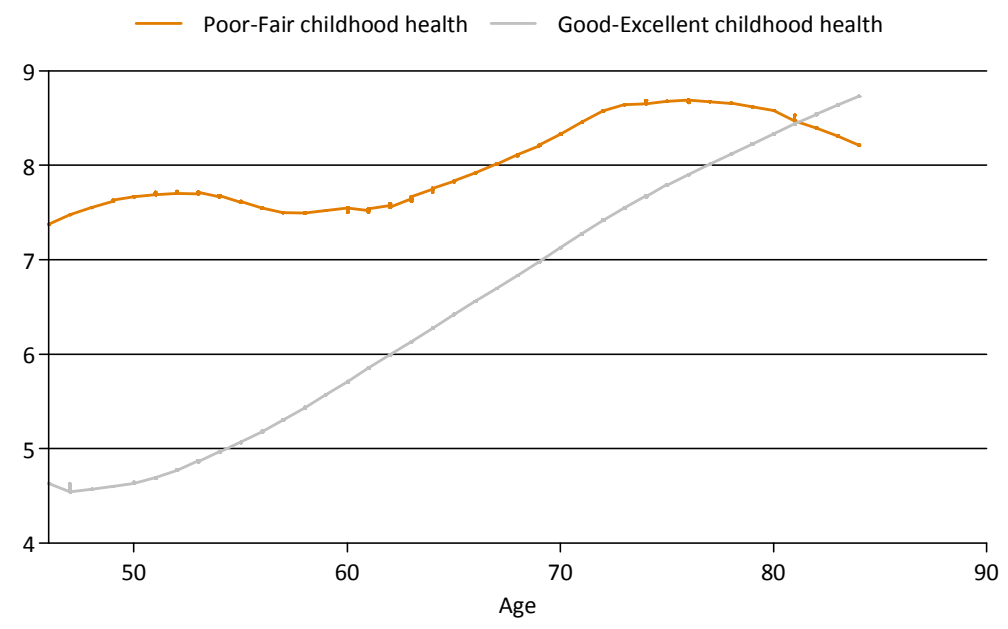

Similar patterns are observed for the age profiles of doctor visits when childhood health is measured by other indicators, such as having had a childhood illness, condition or inpatient stay. We can examine the association between each indicator and health care utilization and payments using regression analysis.

Firstly, we run a negative binomial model of the number of doctor visits (Cameron and Trivedi, 1986) on the pooled data set including our complete set of indi- 
cators of childhood health and circumstances, while also controlling for genderage group dummies and country dummies. Given that we have pooled wave 1 and 2 data, standard errors are computed allowing for clustering at the level of the individual. The results (Table 23.1, column 1) confirm a significant and strong positive correlation of childhood ill-health with the number of doctor visits in middle and old age. All four indicators of health status in childhood are individually strongly significant. In addition, variables proxying health risks and access to health care during childhood are associated with more visits to the doctor. That is, having had a parent who smoked and not having had a usual source of health care during childhood are both associated with increased visits at the 5\% level of significance.

Table 23.1: Association of number of doctor visits with childhood health, without and with control for adult health and socioeconomic status.

Negative binomial regression on pooled wave $1 \& 2$ data

\begin{tabular}{|c|c|c|c|}
\hline $\begin{array}{l}\text { Dependent variable: } \\
\text { Number of Doctor Visits }\end{array}$ & $\begin{array}{r}\text { No control for } \\
\text { Adult Health or } \\
\text { SES }\end{array}$ & $\begin{array}{l}\text { With control for } \\
\text { Adult Health }\end{array}$ & $\begin{array}{r}\text { With control for } \\
\text { Adult Health and } \\
\text { SES }\end{array}$ \\
\hline \multicolumn{4}{|l|}{ Childhood Health } \\
\hline Health reported as fair or poor & $.1873^{* * *}$ & $.0665^{* * *}$ & $.0631^{* *}$ \\
\hline Any illness from question HSOO9 & $.0598 * * *$ & .0096 & .0097 \\
\hline Any illness from question HSOO8 & $.0719 * * *$ & .0162 & .0184 \\
\hline $\begin{array}{l}\text { Inpatient stay } \geq 1 \text { month or } \geq 3 \text { times in } \\
\text { any year }\end{array}$ & $.0880 * * *$ & $.0570 * *$ & $.0569 * *$ \\
\hline \multicolumn{4}{|l|}{ Childhood Health Risks \& Health Care } \\
\hline Parent smoked & $.0372 * *$ & $.0273^{* *}$ & $.0267^{*}$ \\
\hline No usual source of health care & $.0748^{* *}$ & .0027 & .0035 \\
\hline \multicolumn{4}{|l|}{ Adult Health } \\
\hline $\begin{array}{l}\text { Health reported as good, very good or } \\
\text { excellent }\end{array}$ & & $-0.439 * * *$ & $-0.429 * * *$ \\
\hline Smokes currently & & $-.0899 * * *$ & $-0.0907 * * *$ \\
\hline Has stopped smoking & & $.0347^{* * *}$ & $.0393 * * *$ \\
\hline Has a diagnosed chronic illness & & $.4460 * * *$ & $.441 * * *$ \\
\hline Has at least two symptoms & & $.337^{* * *}$ & $.333^{* * *}$ \\
\hline $\begin{array}{l}\text { Number of limitations in (instrumental) } \\
\text { activities of daily living }\end{array}$ & & $.0667 * * *$ & $.0651 * * *$ \\
\hline \multicolumn{4}{|l|}{ Adult Socioeconomic status } \\
\hline Log household income per capita & & & $.0196 * * *$ \\
\hline $\begin{array}{l}\text { Intermediate level of education (ISCED } \\
3-4 \text { ) }\end{array}$ & & & -.0248 \\
\hline High level of education (ISCED 5-6) & & & -.0240 \\
\hline
\end{tabular}




\begin{tabular}{llrr}
\hline $\begin{array}{l}\text { Not working and less than } 65 \\
\text { Observations }\end{array}$ & 39175 & 39175 & $.1401^{* * *}$ \\
$\begin{array}{l}\text { chi-square test for the joint significance } \\
\text { of childhood health and health risks } \\
\text { variables }\end{array}$ & & & 39175 \\
p-value & 0.0000 & 0.0010 & 0.0015 \\
\hline
\end{tabular}

Notes: ${ }^{*} p<0.1{ }^{* *} p<0.05 ;{ }^{* * *} p<0.01$ based on robust standard errors adjusted for clustering at individual level.

All models included gender-age and country dummies. Childhood health in comparison to good, very good or excellent. Minor illnesses HSOO8 are excluded. Health in comparison to fair or poor. Symptoms form SHARE question PH010.

Secondly, we estimate a two-part model of OOP expenditures (Duan et al, 1983; Jones, 2004) consisting of a Logit model to explain the probability of having a positive payments (Table 23.2) and a least-squares regression for positive (log transformed) OOP amounts (Table 23.3).

Indicators of childhood health status are highly jointly significant in explaining both the probability of incurring OOP payments and their level. Having experienced at least one illness from both of the lists of childhood illnesses is significantly correlated with a higher probability of paying OOP for health care (Table 23.2, column 1). Childhood illness is also associated with a higher level of OOP payments, as is having experienced a long, or repeated, stay in hospital during childhood (Table 23.3, column 1).

Conditionally on having positive OOP expenses, having had a parent who smoked is associated with a higher level of OOP payments, at the 5\% level (Table 23.3, column 1). There is no evidence that lack of access to a usual source of health care in childhood is associated greater payments for health care in adulthood. In fact, this variable is negatively associated with the probability of paying out of pocket for health care.

Table 23.2: Association of propensity to incur any out of pocket expenses for health care with childhood health, without and with control for adult health and socioeconomic status (logit model)

\begin{tabular}{lrrr}
\hline $\begin{array}{l}\text { Dependent variable: } \\
\mathbf{1} \text { if any OOP for health care }\end{array}$ & $\begin{array}{r}\text { No control for With control for With control for } \\
\text { Adult Health or } \\
\text { SES }\end{array}$ & & $\begin{array}{r}\text { Adult Health } \\
\text { Adult Health } \\
\text { and SES }\end{array}$ \\
\hline $\begin{array}{l}\text { Childhood Health } \\
\text { Health reported as fair or poor }\end{array}$ & .0778 & -.0277 & -.0181 \\
$\begin{array}{l}\text { Any illness from question HS009 } \\
\text { Any illness from question HSO08 }\end{array}$ & $.1635^{* * *}$ & $.1135^{* * *}$ & $.1003^{* * *}$ \\
$\begin{array}{l}\text { Inpatient stay } \geq 1 \text { month or } \geq 3 \text { times in any } \\
\text { year }\end{array}$ & $.2306^{* * *}$ & $.1587^{* * *}$ & $.1345^{* * *}$ \\
\hline
\end{tabular}


Childhood Health Risks \& Health Care

Parent smoked

$\begin{array}{lll}-.0324 & -0.0388 & -.0385\end{array}$

No usual source of health care

$-.1076^{*}$

$-.1431 * *$

$-.1220 *$

Adult Health

Health reported as good, very good or excel-

lent

Smokes currently

Has stopped smoking

Has a diagnosed chronic illness

Has at least two symptoms

Number of limitations in (instrumental) activities of daily living

$\begin{array}{rr}-.1352^{* * *} & -.1763^{* * *} \\ -.2690^{* * *} & -.2668^{* * *} \\ .0161 & 0.0094 \\ .5875^{* * *} & .5866^{* * *} \\ .5433^{* * *} & .5538^{* * *} \\ -.0388^{* *} & -.0326^{*} \\ & .0946^{* * *} \\ & .1668^{* * *} \\ & .2346^{* * *} \\ & -.0334 \\ & 39175\end{array}$

Adult Socioeconomic status

Log household income per capita

Intermediate level of education

(ISCED 3-4)

High level of education (ISCED 5-6)

39175

39175

Observations

39175

0.0000

0.0001

0.0014

childhood health and health risks variables

p-value

rering at individual level.

All models included gender-age and country dummies. Childhood health in comparison to good, very good or excellent. Minor illnesses HSOO8 are excluded. Health in comparison to fair or poor. Symptoms form SHARE question PH010.

Table 23.3: Association of positive amount of OOP payments with childhood health, without and with control for adult health and socioeconomic status (OLS regression)

\begin{tabular}{|c|c|c|c|}
\hline $\begin{array}{l}\text { Dependent variable: } \\
\text { Log of positive OOP payments }\end{array}$ & $\begin{array}{r}\text { No control for } \\
\text { Adult Health or } \\
\text { SES }\end{array}$ & $\begin{array}{r}\text { With control } \\
\text { for Adult } \\
\text { Health } \mathrm{H}\end{array}$ & $\begin{array}{r}\text { With control } \\
\text { for Adult } \\
\text { lealth and SES }\end{array}$ \\
\hline \multicolumn{4}{|l|}{ Childhood Health } \\
\hline Health reported as fair or poor & $.1450 * * *$ & .0237 & .0276 \\
\hline Any illness from question HSOO9 & $.0762 * * *$ & $.0389 *$ & .0310 \\
\hline Any illness from question $\mathrm{HSOO}$ c & $.0480^{*}$ & .0064 & -.0075 \\
\hline $\begin{array}{l}\text { Inpatient stay } \geq 1 \text { month or } \geq 3 \text { times in any } \\
\text { year }\end{array}$ & $.0690 *$ & .0444 & .0498 \\
\hline Childhood Health Risks and Health Care & $.0417^{* *}$ & $.0326 *$ & $.0314 *$ \\
\hline
\end{tabular}




\begin{tabular}{lrrr}
\hline $\begin{array}{l}\text { Parent smoked } \\
\text { No usual source of health care }\end{array}$ & .0020 & .0137 \\
$\begin{array}{l}\text { Adult Health } \\
\text { Health reported as good, very good or ex- }\end{array}$ & $-.3260^{* * *}$ & $-.3490^{* * *}$ \\
$\begin{array}{l}\text { cellent } \\
\text { Smokes currently }\end{array}$ & -.0227 & -.0218 \\
Has stopped smoking & .0140 & .0116 \\
$\begin{array}{l}\text { Has a diagnosed chronic illness } \\
\text { Has at least two symptoms }\end{array}$ & $.3741^{* * *}$ & $.3712^{* * *}$ \\
$\begin{array}{l}\text { Limitations in (instrumental) activities of } \\
\text { daily living }\end{array}$ & $.2479^{* * *}$ & $.2543^{* * *}$ \\
$\begin{array}{l}\text { Adult Socioeconomic status } \\
\text { Log household income per capita }\end{array}$ & $.1292^{* * *}$ & $.1329^{* * *}$ \\
$\begin{array}{l}\text { Intermediate level of education } \\
\text { (ISCED 3-4) }\end{array}$ & & $.0686^{* * *}$ \\
$\begin{array}{l}\text { High level of education (ISCED 5-6) } \\
\text { Not working and less than 65 }\end{array}$ & & $.0988^{* * *}$ \\
$\begin{array}{l}\text { Observations } \\
\text { chi-square test for the joint significance of } \\
\text { childhood health and health risks vari- } \\
\text { ables } \\
\text { p-values }\end{array}$ & & & $.1705^{* * *}$ \\
\hline
\end{tabular}

Notes: ${ }^{*} p<0.1{ }^{* *} p<0.05 ;{ }^{* * *} p<0.01$ based on robust standard errors adjusted for clustering at individual level.

All models included gender-age and country dummies. Childhood health in comparison to good, very good or excellent. Minor illnesses HSOO8 are excluded. Health in comparison to fair or poor. Symptoms form SHARE question PH010.

The three regressions confirm a significant association between health and health risks in childhood and health care utilization and payments in middle and old age. Individuals who report poorer childhood health status, childhood illness, extended or repeated inpatient stay during childhood, or being exposed to parental smoking visit their physicians more often and incur higher OOP payments for health care beyond the age of 50. The regressions also provide some evidence that health care in childhood is associated with health care utilisation in middle and old age. Those that did not have a usual source of health care during childhood visit the doctor more often as adults. 


\subsection{Exploring mechanisms responsible for the association}

Why is childhood health status correlated with health care utilisation and payments in middle and old age? The most obvious mechanism is through adult health, which, according to the existing literature, could be direct (Kuh and Wadsworth, 1993; Barker, 1995) and/or via socioeconomic status (SES) (Marmot et al, 2001; Case et al., 2005). Another possible mechanism is from childhood health problems to socioeconomic status and subsequently health care seeking behaviour, conditional on health care needs. In spite of the universal nature of European health care systems, the widespread commitment to equity in access to health care and the relatively low level of OOP payments in many countries, socioeconomic differences in the utilisation of health care, particularly specialist care, remain (Van Doorslaer et al, 2004). These inequalities may reflect, amongst other factors, educational differences in health expectations and knowledge of health care. But conditional on measured adult health and SES, health care utilisation may remain correlated with childhood health. In part, this could arise from a direct causal effect, perhaps because an early-life experience of ill-health and health care permanently influences preferences for the receipt of care from doctors and hospitals. Of greater importance, most likely, is an ability of reported child health to provide information on variation in health status over and above that which can be captured by the indicators included in a survey, even one so rich in health indicators as SHARE. In this case, childhood health indicators provide valuable information on inherent health status that could prove useful in a number of contexts. For example, it might be used as a determinant of the demand for health insurance.

With the aim of assessing the relative importance of these different mechanisms, we observe how the association between the childhood health indicators and doctor visits and OOP payments change as we sequentially add controls for adult health status (column 2 in Tables 23.1-23.3) and then socioeconomic status (column 3 in Tables 23.1-23.3). If childhood health has a direct impact on health care use in middle and old age, or if it provides information on inherent health status over and above that contained in the indicators of adult health, then after the controls are added the childhood health variables will continue to have significant effects on health care use at older age.

As expected, the indicators of adult health status are strong predictors of doctor visits (Table 23.1, column 2). Controlling for health in adulthood, the coefficients on the indicators of childhood health fall greatly in magnitude but, together with exposure to parental smoking, they remain jointly significantly correlated with doctor visits. Individually, poor-fair self-assessed childhood health status and long, or repeated, inpatient stays remain significant positive predictors of the number of doctor visits. Exposure to parental smoking also remains significantly correlated with increased visits to the doctor. Since the adult health indicators include current and past smoking status, this is suggestive of a direct impact of parental smoking on health care utilisation in adulthood over and above that through 
the influence on the persons own smoking behaviour. Lack of access to a usual source of health care during childhood is no longer significantly correlated with doctor visits once control is made for adult health status. This implies that lack of access to care in childhood is negatively correlated with health in adulthood and this is shown explicitly for all indicators of adult health in Table 23.4 (column 1). This is suggestive of inadequate treatment of childhood health problems having long terms consequences for health and, in turn, utilization of health care.

Adding controls for SES has less effect on the magnitude and the significance of the coefficients of the childhood health variables. The indicators remain highly jointly significant and both reported poor-fair childhood health status and childhood inpatient stay continue to be positively correlated with increased doctor visits, as does parental smoking at the $10 \%$ level of significance. These results suggest that childhood experience of illness has a long-lasting direct impact on health care seeking behaviour and/or that the childhood health indicators operate as proxies for current inherent health that is not fully captured by contemporaneous health indicators.

With respect to the explanation of the propensity to spend OOP on health care (Table 23.2, column 2), upon the inclusion of adult health status variables, most of the coefficients of the childhood health variables fall in magnitude but both indicators of illness in childhood remain significant and the set of childhood health measures are still highly jointly significant. Joint significance of the child health and health risks indicators is also maintained in explanation of the level of OOP payments, but in this case only two of the indicators remain individually significant at the reduced level of $10 \%$ (Table 23.3, column 2). As with doctor visits, the introduction of SES indicators has little effect on the childhood health coefficients and their joint significance.

Table 23.4: Access to health care in childhood and its correlation with indicators of health status in adulthood by major European regions and average share of the population with total medical coverage in 1960

\begin{tabular}{|c|c|c|c|c|c|}
\hline & $\begin{array}{r}\text { All } \\
\text { countries }\end{array}$ & $\begin{array}{r}\text { Southern } \\
\text { Europe }\end{array}$ & $\begin{array}{l}\text { Central } \\
\text { Europe }\end{array}$ & $\begin{array}{r}\text { Northern } \\
\text { Europe }\end{array}$ & $\begin{array}{l}\text { Eastern } \\
\text { Europe }\end{array}$ \\
\hline $\begin{array}{l}\text { Percentage with no usual source } \\
\text { of health care during childhood }\end{array}$ & $5.69 \%$ & $8.37 \%$ & $4.87 \%$ & $3.23 \%$ & $7.24 \%$ \\
\hline \multicolumn{6}{|c|}{$\begin{array}{l}\text { Pearson's Correlation b/w not having usual source of health care in childhood and indicators of } \\
\text { health in adulthood }\end{array}$} \\
\hline $\begin{array}{l}\text { Health reported as good, very } \\
\text { good or excellent }\end{array}$ & $-0.0372^{*}$ & 0.0011 & $-0.0381^{*}$ & -0.0013 & $-0.115^{*}$ \\
\hline Has a diagnosed chronic illness & $0.0173^{*}$ & -0.0017 & $0.0319^{*}$ & 0.0004 & $0.0826^{*}$ \\
\hline Has at least two symptoms & $0.0285^{*}$ & 0.0073 & $0.0187^{*}$ & $0.0232 *$ & $0.1148 *$ \\
\hline
\end{tabular}




\begin{tabular}{lrrrrr}
\hline Limitations in (instrumental) ac- & & & & & \\
tivities of daily living & $0.0571^{*}$ & $0.0753^{*}$ & $0.0281^{*}$ & 0.0051 & $0.1196 *$ \\
$\begin{array}{l}\text { Observations } \\
\begin{array}{l}\text { Average share of the population } \\
\text { with total medical coverage in }\end{array}\end{array}$ & & $19^{\prime} 386$ & $144^{\prime} 914$ & $9^{\prime} 505$ & $3^{\prime} 370$ \\
\begin{tabular}{l}
1960 (OECD 2008) \\
\hline
\end{tabular} & & $61.70 \%$ & $74.24 \%$ & $88.70 \%$ & $\begin{array}{r}\text { not } \\
\text { available }\end{array}$ \\
\hline
\end{tabular}

Notes: All models included gender-age and country dummies. Childhood health in comparison to good, very good or excellent. Minor illnesses HSOO8 are excluded. Health in comparison to fair or poor. Symptoms form SHARE question PHO1O.

* Indicates Chi-square test rejects null of independence at the $5 \%$ level or lower

In summary, we find that poor childhood health does predict greater health care utilisation and payments in middle and old age. This predictive ability falls substantially, but remains significant, when adult health status is controlled for. Controlling for education and socioeconomic status has a much smaller impact on the correlation, suggesting there is little impact from childhood health to SES and subsequently to health care utilisation. There is also some evidence that inadequate treatment of childhood health problems has long terms consequences for health and, in turn, utilization of health care.

\subsection{Does the association vary across Europe?}

As suggested in the introduction, differences in the coverage and effectiveness of health care systems during the childhood of the SHARE cohorts may result in cross-country variation in the degree to which childhood health problems predict health care use in middle and old age. To investigate this, we distinguish four geographic areas: Northern (SE, DK, NL), Central (BE, DE, AT, FR, CH), Southern (ES, IT, GR) and Eastern (CZ, PL) countries. Figure 23.2 plots the age profile of mean number of doctor visits by self-assessed childhood health status for the four areas.

Figure 23.2: $\quad$ Mean number of doctor visits by age split by health status in childhood for European regions 
— Bad childhood health - Good childhood health
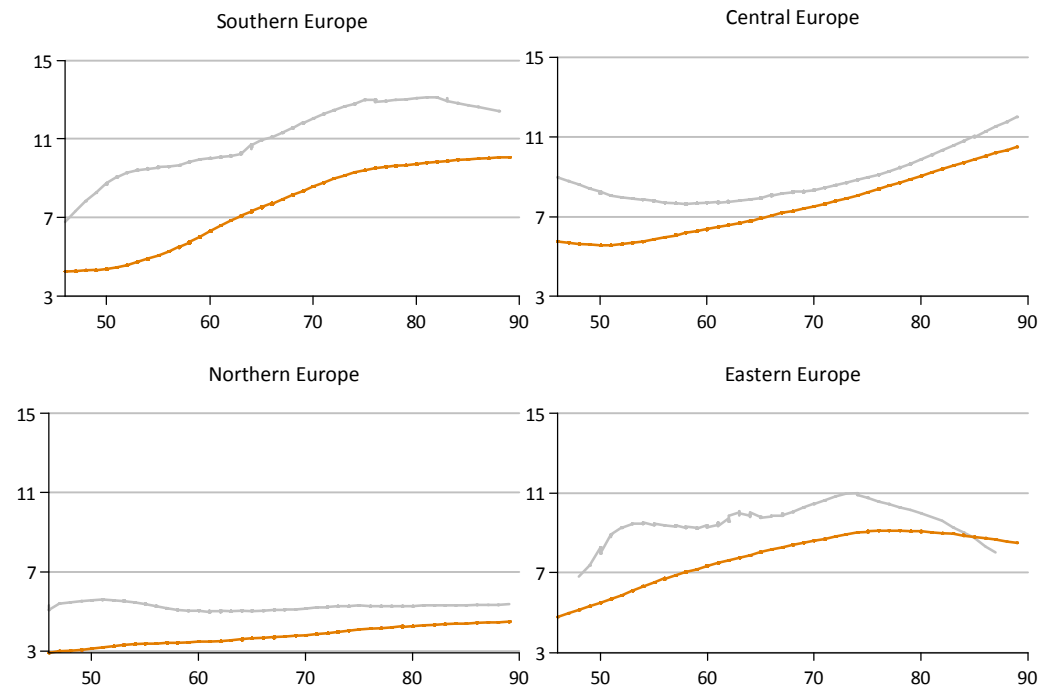

At all ages, the average number of visits to a doctor is lowest in the Northern European countries and is highest in Southern Europe. In all four geographic areas, those who report being in poor-fair health during childhood visit the doctor more often in middle and old age than those who report being in good-excellent health during childhood. The difference is much larger in Southern Europe than it is in the other regions, and while the disparity decreases as people get older in Northern, Central and Eastern Europe, this is not true in Southern Europe. These differences, at least in part, seem to be attributable to differences in the propensity to report poor childhood health status. Only $5 \%$ of respondents in the Southern countries report poor-fair health status in childhood whereas the respective percentages are $6.8 \%, 9.5 \%$ and $10 \%$ in Eastern, Northern and Central countries. Consequently, the disparity in health status between those reporting poor-fair and those reporting good-excellent would be expected to be greater in Southern countries and the greater disparity in health care utilization in this region may reflect this.

Running the same regression models for each geographic area separately reveals that, after controlling for adult health, childhood health and health risk indicators are significant predictors of doctor visits and OOP payments in Southern and Central Europe but not in Northern and Eastern Europe. Respondents from Southern and Eastern Europe are less likely to have had access to a usual source of care during childhood (Table 23.4, columns 2-5) and this is a predictor of higher OOP payments only in these two regions. Southern Europe is also the region in which, in 1960, the lowest proportion of the population was enjoying full medical coverage (Table 23.4). This suggests, although it certainly does not confirm, that 
the Southern European cohorts experienced less adequate treatment of childhood health problems resulting in long term consequences for health and, in turn, health care payments.

\subsection{Conclusion and policy relevance}

We have shown that childhood health is a strong predictor of health care utilization and payments in middle and old age. This predictive ability is considerably weakened when control is made for measured health in adulthood, although it remains significant. Controlling for socioeconomic status has little or no effect. The correlation is stronger in Southern and Central Europe than it is in Northern and Eastern countries.

The fact that correlation holds in Southern Europe, and in some extent in Central Europe, but not in Northern Europe may be interpreted as indicative of childhood health problems having longer lasting implications in countries that were further from universal health care during the childhood of the SHARE cohorts of older individuals. In 1960, when the youngest of the SHARE cohort was around 5 years old, the proportion of the population with total medical coverage was lowest in Southern Europe and highest in Northern Europe (Table 23.4). These cross European differences in coverage correspond both with those in the proportion of the SHARELIFE respondents reporting not having a usual source of health care in childhood and with the strength of the association between childhood ill-health and health care utilisation in adulthood. This suggests that the correlation between childhood health and adult health and health care utilisation may be weaker for cohorts younger than the SHARE sample. Medical coverage is now universal throughout Europe, the effectiveness of medicine has increased tremendously and barriers to access have been reduced. Childhood health problems would therefore be expected to leave less of a lasting impact than they did in the past.

Our analysis is pertinent to the much discussed health care costs of ageing populations. Ability to curtail these costs will depend, among other things, on the extent to which health care use in old age is driven by health experiences in childhood. Our results are consistent with childhood health conditions having longlasting effects on health, and consequently utilisation of health care. If there are indeed such very long lived consequences of childhood illnesses, then there would be very long lag times in realizing the returns to timely and effective policy interventions. By the same token, the magnitude of these lifetime returns could be very large. Improving childhood health in populations now will lead to future cohorts costing less in old age than do their current counterparts.

But we should be careful about rushing to such bold implications. It could very well be that childhood health correlates with health care utilisation in old age because both reflect inherent health status. Variation in childhood health reflects the variation in the physiological and psychological robustness of individuals that is 
present throughout the lifetime and generates persistent differences in the utilisation of health care. On this interpretation, the correlation we observe does not necessarily indicate opportunities for long term returns to effective childhood health care. It does mean that variation in lifetime health care costs may be predictable from an early age. Depending upon whether information on childhood health problems is kept private, or must be shared with insurers, this will have important implications for the efficiency and/or equity of health insurance.

\section{References}

Barker, D.J.P., 1995. Fetal origins of coronary heart disease. British Medical Journal, Vol. 311(6998), pp. 171-174.

Cameron, A., Trivedi, P. Econometric models based on count data: comparisons and applications of some estimators and tests. Journal of Applied Econometrics, Vol. 1, pp. 29-54.

Case A, Fertig A, Paxson C, 2005. The lasting impact of childhood health and circumstance. Journal of Health Economics, Vol. 24, pp. 365-389.

Duan, N., Manning, W.G., Morris, C.N. and Newhouse, J.P. A comparison of alternative models of the demand for health care. Journal of Business and Economics Statistics, 1983. Vol. 1, pp. 115-126.

Jones, A.M. Health Econometrics in A.J. Culyer and J.P. Newhouse, Handbook of Health Economics, Vol. 1, 2000. Amsterdam, Elsevier Science.

Kuh DJ, Wadsworth ME, 1993. Physical health status at 36 years in a British national birth cohort. Social Science and Medicine, Vol. 37(7), pp. 905-916.

Marmot M, Brunner S, Hemingway S, 2001. Relative contributions of early life and adult socioeconomic factors to adult morbidity in the Whitehall II study. Journal of Epidemiology and Community Health, Vol. 55, pp. 301-307.

Van Doorslaer E, Koolman X, AM Jones, 2004. Explaining income-related inequalities in health care utilisation in Europe: a decomposition approach, Health Economics 2004. Vol. 13(7). 